\title{
ESCENAS
}

(ensayos)

\section{El culo a modo de trompeta: Dante Alighieri en James Joyce}

FIGURAS REVISTA ACADÉMICA DE INVESTIGACIÓN

ISSN 2683-2917

Vol. 3, núm. 1, noviembre 2021-febrero 2022

https://doi.org/10.22201/fesa.figuras.2021.3.1

Esta obra está bajo una licencia

(c) $\$(0)$ Creative Commons Atribución-NoComercial-

Compartirlgual 4.0 Internacional

"As reply he made a bugle of his ass": 1

Dante Alighieri on James Joyce

https://doi.org/10.22201/fesa.figuras.2021.3.1.197

\section{Ernesto Lumbreras}

Los personajes que transitan y conversan en la novela peripatética del Ulises (1922) de James Joyce, son lectores a conciencia de los clásicos de la literatura. En el capítulo Ix de la obra maestra del escritor irlandés -número, por cierto, de alto valor simbólico en la Commedia de Dante- se habla de Goethe y su Wilhelm Meister, de Milton y su Paraíso perdido, de Shakespeare y su Hamlet al igual que de otros poetas, filósofos y

1 Susan Mitchell. escritores de épocas gloriosas. En el comienzo del citado capítulo, en el diálogo entre Stephen Dedalus y John Eglinton surge un verso extraño o desconcertante, hasta cierto punto cómico y pícaro, de la autoría del poeta florentino citado por Joyce en el toscano de principios del trecento en el que fue escrito:

Ed elli avea del cul fatto trombetta.

¿Cómo se traduce dicho verso? No hay demasiada complejidad en términos de sintaxis o, incluso, de musicalidad, para verter al español o al inglés o al francés esas once sílabas estruendosas. Se trata del último verso del Canto xxI del Infierno; allí, Dante y Virgilio se encuentran en el octavo círculo entre diablos que torturan y persiguen a las almas pecadoras que hicieron fortuna especulando y traficando bienes. Por varias razones, lo que sucede aquí, en esta caminata por el primer reino de ultratumba, tiene un 
giro categórico: un elemento bufo y grotesco surge de pronto y desvanece por unos instantes la pesadumbre trágica, plena de terrores y angustias que el poeta italiano nos comparte en la primera cantiga de su altísimo libro. Al final de dicho canto, Virgilio convence a los demonios del destino celestial de la misión y pide que los dejen seguir su camino. Una decena de diablos, entonces, escolta a los dos poetas que avanzan con pavor y sospechas de traición; los demonios, toda malicia e ingenio arrabaleros, atemorizan con burlas y amenazas principalmente a Dante. Así, como si fuera una clave entre ellos, el jefe de los ángeles infernales alerta a sus compinches para iniciar otra oleada de espanto y para eso:

él usó el culo a modo de trompeta.

(versión de Ángel Crespo)

En una novela como el Ulises, criticada por obscena y escatológica, el verso en cuestión vino como anillo al dedo. En la vida de amante, el imaginario erógeno de James Joyce -revelado en toda su plenitud en las cartas a Nora Barnacle- concedía un lugar de privilegio a las flatulencias; en una de esas misivas, la escrita el 2 de diciembre de 1909, en recuerdo de ciertas experiencias de alcoba, libérrimas y desenfrenadas, el escritor recuerda: "he pensado en ti haciéndome gestos sucios con los labios y con la lengua, provocándome con ruidos y caricias obscenas y haciendo delante de mí el más sucio y vergonzoso acto del cuerpo. ¿Te acuerdas del día en que te alzaste la ropa y me dejaste acostarme debajo de ti para ver cómo lo hacías? Después quedaste avergonzada hasta para mirarme a los ojos." En ese epistolario de ida y vuelta, los amantes incendian la caldera de la imaginación, crean y recrean rituales del coito y de la gimnasia del acoplamiento, pero sobre todo, integran a la pasión erótica lo obsceno, lo sucio y lo pornográfico. Por supuesto, en esos pasajes lascivos hay juego e ironía, complicidad e irreverencia. Joyce se permite llamar a su mujer "mi dulce e indecente pedorrita", y no se detiene en celebrar y manifestar añoranza por "oír y oler los sucios y sonoros pedos de niña haciendo pop pop al salir de tu bonito culo y desnudo de niña."

\section{Algunos traductores de la Commedia de nuestra lengua, han traducido el singular verso con eufemismos ridículos cargados de moralina y contención expresiva.}

Con semejantes cartas credenciales, Joyce se identificó con el endecasílabo dantesco desde la primera vez que lo leyó. Tomando en cuenta su afición por el bel canto -el autor de Dublineses pudo ser un cantante de éxito-, el conocimiento regular del italiano, muy posiblemente permitió al irlandés comprender y traducir a su lengua el citado verso. Lo leyó, lo escuchó y lo paladeó sin tapujos y con deleitación: Ed elli avea del cul fatto trombetta. Sin embargo, algunos traductores de la Commedia de nuestra lengua, han traducido el singular verso con eufemismos ridículos cargados de moralina y contención expresiva. Por ejemplo, en la edición de Aguilar, Juan de la Pezuela Conde de Cheste lo tradujo en 1865 con estas palabras: usando del de atrás como trompeta. Con la misión de mejorar y rectificar la versión del Conde de Cheste, el argentino Bartolomé Mitre dedicó buena parte de su vida, entre campañas de guerra y de política, en traer a un castellano más universal el poema dantesco; a todas luces, su traducción del endecasílabo citado goza de mejor música y estructura: $y$ el jefe de su culo hizo trompeta. Más próximos a nuestros días, Abilio Echeverría, en la edición de Alianza de 1995, arrastrando una posible errata, traduce el verso celebrado por Joyce de esta forma: que a su vez de su culto (sic) hizo trompeta. En la otrora célebre Ediciones Carlos Lohlé, con motivo del séptimo centenario del natalicio del poeta toscano, Ángel J. Battistessa emprendió la misión de traer 
a nuestra lengua la obra maestra de las letras italianas; sin comprometerse con la rima y la métrica, el argentino se apegó al sentido del poema y tradujo el verso en cuestión en formato dodecasílabo: y el jefe de su culo hacía trompeta.

Es curioso que en la edición prosificada del poema, en las Obras completas de Dante Alighieri (1994), de la Biblioteca de Autores Cristianos, su traductor, Nicolás González Ruiz (1897-1967), periodista católico de filiación franquista, traduzca sin tapujos -y con añadidos - el verso 139 del Canto XXI de esta forma: $y$ él dio la señal de partida usando el ano como trompeta. En la edición vasconcelista de La divina comedia (1921), que no anota el crédito del traductor, adornado con bellas viñetas y capitulares -apuesto que son de José Clemente Orozco-, el verso bufo se traduce vía esta oración: y este se sirvió de su ano a guisa de trompeta. Por último, en el carrusel de versiones y aproximaciones, la edición en prosa del poema, "una adaptación para todas las edades" realizada por Elena Martínez para el sello madrileño de GADIR, la línea y su contexto comentados se reducen a este párrafo que me recuerda cierto pasaje de la carta de Joyce a su mujer: "Los diablos, mientras esperaban la orden de moverse, sacaban la lengua entre los dientes haciendo ruidos grotescos y Barbariccia, que era aún más vulgar, como señal para partir hizo con su culo el ruido de una trompeta."

\section{El célebre poema de Dante reúne lo sublime y lo mundano, lo muy mundano de los hombres que aspiran a vivir bajo el milagro del sol y de las demás estrellas.}

En 1993, a iniciativa de James Merrill y Peter Hooten, se convocó a 20 poetas de lengua inglesa para traducir los 34 cantos del Infierno, con el propósito de reunir dichas versiones en un volumen publicado, ese mismo año, bajo el sello de The Ecco Express; entre los que aceptaron el llamado dantesco se encontraba Seamus Heaney, Galway Kinnell, Mark Strand, Charles Wright, Robert Pinsky, W.S. Merwin, Robert Hass y otros más; Susan Mitchell fue la encargada de traducir el Canto XxI y, en consecuencia, el verso que hemos venido citando en sus múltiples variantes del castellano; la versión de la poeta neoyorkina se materializó en la lengua de Blake de esta forma concisa y sin ambigüedades: As reply he made a bugle of his ass.

Como quiera que sea, el célebre poema de Dante reúne lo sublime y lo mundano, lo muy mundano de los hombres que aspiran a vivir bajo el milagro del sol y de las demás estrellas; a no dudarlo, la cercanía con Ezra Pound, dantófilo y dantólogo irredento, alentó en el tráfico de influencia de James Joyce, la presencia de la Commedia como una de las pasiones humanas -divinamente humanas- que siguen presentes en las interrogantes y encrucijadas del hombre moderno. 